\title{
THE EFFECT OF THE CONSUMER DECISION-MAKING PROCESS ON THE PERCEIVED VALUE TOWARD SLOW FASHION
}

\author{
Puiu lonela-Andreea ${ }^{1}$
}

\begin{abstract}
Slow fashion designates a new paradigm in the clothing industry that promotes the importance of fashion goods realized with natural and durable products, empowering consumers to use the purchased clothes for a longer time, decreasing, in this case, the environmental and societal impact of fashion pieces. Even if it designates the opposite of fast fashion production, the slow fashion notoriety is not remarkably high among consumers. This study proposed to examine the effect of the consumers' decision-making process on the noticed value toward slow fashion. In this regard, we considered multiple decision-making constructs and tested their impact on consumers' perceived value toward slow fashion. Also, we examined if there are discrepancies in the perceived value toward slow fashion based on gender. A survey was designed and administrated in Romania to a sample of 330 consumers aged between 18-25. We applied to the collected data exploratory analysis to identify the distribution of manifest variables into factors, followed by confirmatory factor analysis to test the performance of the obtained factors. Finally, we tested the proposed hypotheses using the structural equation model procedure. Were identified seven dimensions that compose the decision-making process of the consumers, namely, recreational shopping, perfectionism, brand knowledge, over choice confusion, fashion awareness, impulsive buying, and brand loyalty. Also, were found three dimensions that constitute the consumers' perceived value toward slow fashion, namely, emotional, social, and financial dimensions. The results showed that over choice confusion exhibits a positive effect on the emotional and financial value; fashion awareness manifests a positive effect on the social value, while brand loyalty manifests a positive impact on the financial value. In the case of gender impact on the emotional value, it was identified that, if a respondent is a female, the influence is positive and statistically significant.
\end{abstract}

Key words: Fashion Industry, Consumer Behavior, Slow Fashion, Structural Equations, Innovation Resistance.

JEL Classification: C38, D12, L67, P36

\section{Introduction}

There is remarked an increase in the number of consumers that became more conscious of the environmental and scarcity difficulties that may affect their lifestyles and inevitably their consumption behavior. An industry that is facing this problem is the fashion industry that paid meaningful attention to sustainability and ethical issues, aggressively promoting this awareness also to fashion producers.

In this context, developed slow fashion as a widespread reaction to the fast fashion movement. Slow fashion appoints the process of creating and consuming fashion items ethically and consciously by introducing an alternative method of technological production to reduce as much as possible the waste of available resources and to find alternative fabrics that present regenerable properties. Essentially, slow fashion connects social and environmental awareness with

Corresponding author:

${ }^{1}$ The Bucharest University of Economic Studies,

Economics I Doctoral School, Bucharest, Romania.

E-mail: andreeaipuiu@gmail.com

ORCID: https://orcid.org/0000-0003-3461-1144 the responsibility for the future and the satisfaction of getting and wearing attractive, well-realized, and long-lasting fashion items, contrary to the immediate satisfaction produced by fast fashion consumption.

In the research process that we have undertaken, we proposed to realize an inventory of the consumers' decision-making influence on the perceived value toward slow fashion. In this regard, we applied exploratory factor analysis, finding seven components that encompass the decision-making process and three factors that compose the perceived value toward slow fashion. Secondly, it was applied a confirmatory factor analysis followed by hypotheses testing using the structural equation model procedure.

In the first section of the study, it was realized a summary of the existing studies in the domain, followed by the research method, results, and conclusions. In the last section were presented practical implications and limitations of the present research. 


\section{Theoretical foundation}

People confront every day, consciously or unconsciously, with decisions. When it comes to the process of purchasing goods, consumer choices are influenced by mental and cognitive biases regarding their shopping experience and purchase decisionmaking techniques (Sproles, 1985; Stankevich, 2017). In this respect, the existing literature (Sproles and Kendall, 1986) identified eight dimensions that could characterize the consumer's decision-making process, namely recreational shopping consciousness, perfectionism, brand consciousness, confusion by over choice, fashion consciousness, price consciousness, impulsiveness, and brand loyalty. In the following, we would expose the implications of each dimension.

The first dimension, recreational shopping experience, refers to the satisfaction that arises from the buying session, consumers looking for new emotional experiences, and adventure during the shopping activity. The second dimension, perfectionism, refers to the people's tendency toward maximization and realization of the best choices, considering the available resources. Perfectionist consumers search for highquality products that provide them with a greater added value.

The third dimension, brand consciousness, describes that purchase decision that is influenced by the rename of a brand, consumers getting only the most well-known brands that have the higher prices, this last aspect being considered a sign of quality. Brand consciousness is also managed by the consumer's desire to adhere to a social class or to confirm his social status (Goldsmith et al., 2010).

Another aspect that could affect the decision-making process is the existence of multiple available options. In this case, the consumer is oversaturated with various options from whom he can choose (Claudy, 2011; Puiu, 2019). The decision process becomes embarrassed and produces interference in the consumer subconscious.

The other two aspects that influence the consumer decision-making process are fashion consciousness and price consciousness. Fashion consciousness refers to people's inclination to favor the newest styles and the latest appeared fashion trends. Price awareness limits the bias toward impulsive and irrational shopping because consumers are sensitive to the financial part.

Impulsiveness appoints people's inclination to realize purchase decisions irrationally. Therefore, buyers assume those choices without examining all factors that affect the purchase process and implicitly its unfavorable effects. The last dimension, brand loyalty, describes people's tendency toward attempting consistency and the default choice. So, consumers prefer to buy previously recognized and tested products or brands rather than trying new ones, even if the last category of products will supply them with a higher satisfaction or economic utility.
We expect that the previously presented dimensions will reveal a significant impact on the consumer's perceived value toward slow fashion, even there will be a positive or a negative influence. This perceived value was identified as being the overall efficacy of a product based on consumer investment and its expected returned earnings. Consumers perceived value toward a particular output includes four dimensions: the emotional, social, price, and quality values.

Emotional value refers to the affective sensations that consumers manifest toward products. It is known that consumers exhibit attachment to the products that they own (Tversky and Kahneman, 1991). The social value shows people's wish to be part of a community. The social value includes the products that consumers buy and use to be accepted by their social group and realize a good impression on their peers.

Price value appoints the cost-benefit investigation to verify if a product creates the proper value for its implicit cost. The last dimension, quality value, refers to the overall perceived quality of a product and whether this quality produces satisfaction to the consumer or not.

Considering that we are examining the influence of the decision-making dimensions on the perceived value toward fashion, we expect to register differences among males and females because their attitude toward fashion is different. Considering previously exposed theoretical aspects, we hypothesized the following statements that will be tested.

\section{Hypotheses}

$\mathbf{H}_{\mathbf{1}}$ : Decision-making components manifest a statistically significant influence (eighter negative or positive) on the consumers' perceived values toward fashion.

$\mathbf{H}_{2}$ : Gender manifests a positive influence on the perceived values of slow fashion.

\section{Research methodology}

\subsection{The instrument, sample, data collection and, method of analysis}

To collect data, it was applied a questionnaire that connects scales validated in previous research. To measure the consumer decision-making styles, it was adjusted the scale validated in Sproles and Kendall's study (1986). It was evaluated the consumers' perceived value toward slow fashion applying the perceived value scale, adapted from Sweeney and Soutar (2001). The items were ranked using a sevenpoint Likert scale, where one belongs to strong disagreement and seven to strong agreement. The original survey was translated into Romanian.

There was gathered a total of 330 responses from Romanian consumers; aged between 18 and 25 years (the mean age of the participants was 23.38). Regarding the gender distribution in the sample, 
Vol. 2 No. 1, 2021

Three Seas Economic Journal

Table 1

Sample characteristics

\begin{tabular}{|c|c|c|c|}
\hline \multirow{2}{*}{ ITEM } & \multirow{2}{*}{ CLASSIFICATION } & \multicolumn{2}{|c|}{$\mathrm{N}=330$} \\
\hline & & No. & $\%$ \\
\hline \multirow{2}{*}{ Gender } & Women & 262 & $79.00 \%$ \\
\hline & Men & 68 & $21.00 \%$ \\
\hline \multirow{2}{*}{ Residence } & Urban & 225 & $68.3 \%$ \\
\hline & Rural & 105 & $31.7 \%$ \\
\hline \multirow{7}{*}{ Income } & Lower than $\$ 225$ & 149 & $44.9 \%$ \\
\hline & Between $\$ 225-\$ 450$ & 58 & $17.5 \%$ \\
\hline & $\$ 450-\$ 675$ & 47 & $14.2 \%$ \\
\hline & $\$ 675-\$ 900$ & 30 & $9.00 \%$ \\
\hline & $\$ 900-\$ 1125$ & 10 & $3.00 \%$ \\
\hline & $\$ 1125-\$ 1350$ & 16 & $4.80 \%$ \\
\hline & Greater than $\$ 1350$ & 20 & $6.60 \%$ \\
\hline \multirow{5}{*}{ Frequency Clothes Purchase } & Weekly & 8 & $2.60 \%$ \\
\hline & At two weeks & 19 & $5.50 \%$ \\
\hline & Monthly & 90 & $27.1 \%$ \\
\hline & Every season & 69 & $20.8 \%$ \\
\hline & Where it is needed & 144 & $43.4 \%$ \\
\hline
\end{tabular}

Source: Author's calculation, 2020

we encountered 262 women $(79.00 \%)$ and 68 men (21.00\%), while regarding the residence: 225 of the respondents $(68.3 \%)$ were from the urban areas, while only 105 of them $(31.7 \%)$ were from rural areas. Regarding their county of residence, most of them were from Bucharest (18.81\%), followed by Iași (13.86\%), Bacău (6.6\%), Neamț (5.28\%), Brașov (5.00\%) and Mureș (5.00\%).

Regarding the monthly net revenue, $44.9 \%$ recorded a net monthly income lower than $\$ 225$, while only $6.6 \%$ reported an income higher than $\$ 1350$. Concerning the frequency of clothes purchase, $43.40 \%$ stated that they purchase clothes when there is needed, while $27.10 \%$ used to buy clothes weekly. We exposed descriptive statistics of the sample in Table 1.

Before testing the hypotheses, it was conducted exploratory factor analysis using the minres extraction procedure and oblimin rotation, followed by reliability tests. There were eliminated from the analysis factor loadings lower than 0.40. Further, it was employed the confirmatory factor analysis to examine the performance of the obtained constructs in the exploratory analysis, followed by fit indices calculations. To test the stated hypotheses, it was employed a structural equation procedure. All statistical procedures were tested using the R Software (R Core Team, 2020).

\section{Findings}

\subsection{Preliminary analysis}

The first part of the research method started with a graphical representation of the presumed correlations among the investigated dimensions. It was observed that most of the variables correlate positively, not being registered scores lower than 0.3 to indicate the lack of association among investigated variables.

In the next step, it was checked the appropriateness of the sample size to run the exploratory factor analysis employing the Kaiser Mayer Olkin Statistics (KMOS) for both scales included in the questionnaire. The KMOS registered meritorious scores of 0.84 (decision-making style), respectively, 0.88 (perceived value). The parallel analysis suggested that seven factors appear from the decision-making style dimension and three factors from the perceived value dimension.

In the case of the decision-making dimension, the primary factor explained $10.40 \%$ of the variance, while the remaining four factors accounted for $9.20 \%$, $8.40 \%, 8.00 \%, 7.20 \%, 5.90 \%$, 5.00\%. The Cronbach Alpha registered scores among 0.64 and 0.89 (Table 2). Regarding the fit indices, the Tucker-Lewis Index of factoring reliability encounters a value of 0.929. The root means square of the residuals (SRMR) registers a score of 0.03 , while the root mean square of error approximation (RMSEA) a value of 0.049 .

Regarding the perceived value dimension, the primary factor explained $24.30 \%$ of the variance, while the other two factors explain $23.20 \%$, respectively $19.10 \%$. For this scale, we registered Cronbach Alpha scores among 0.86 and 0.92 . For this scale, the Tucker Lewis Index registers a value of 0.936 . The SRMR registers a value of 0.02 , while RMSEA registers a score of 0.088 .

After the exploratory analysis, we employed the confirmatory factor analysis, using the maximum likelihood estimator, to verify the performance of the already obtained factors. To diagnose the model, we considered the following indices: Goodness of Fit and Adjusted Goodness of Fit Indices (GFI $\geq 0.95$ 

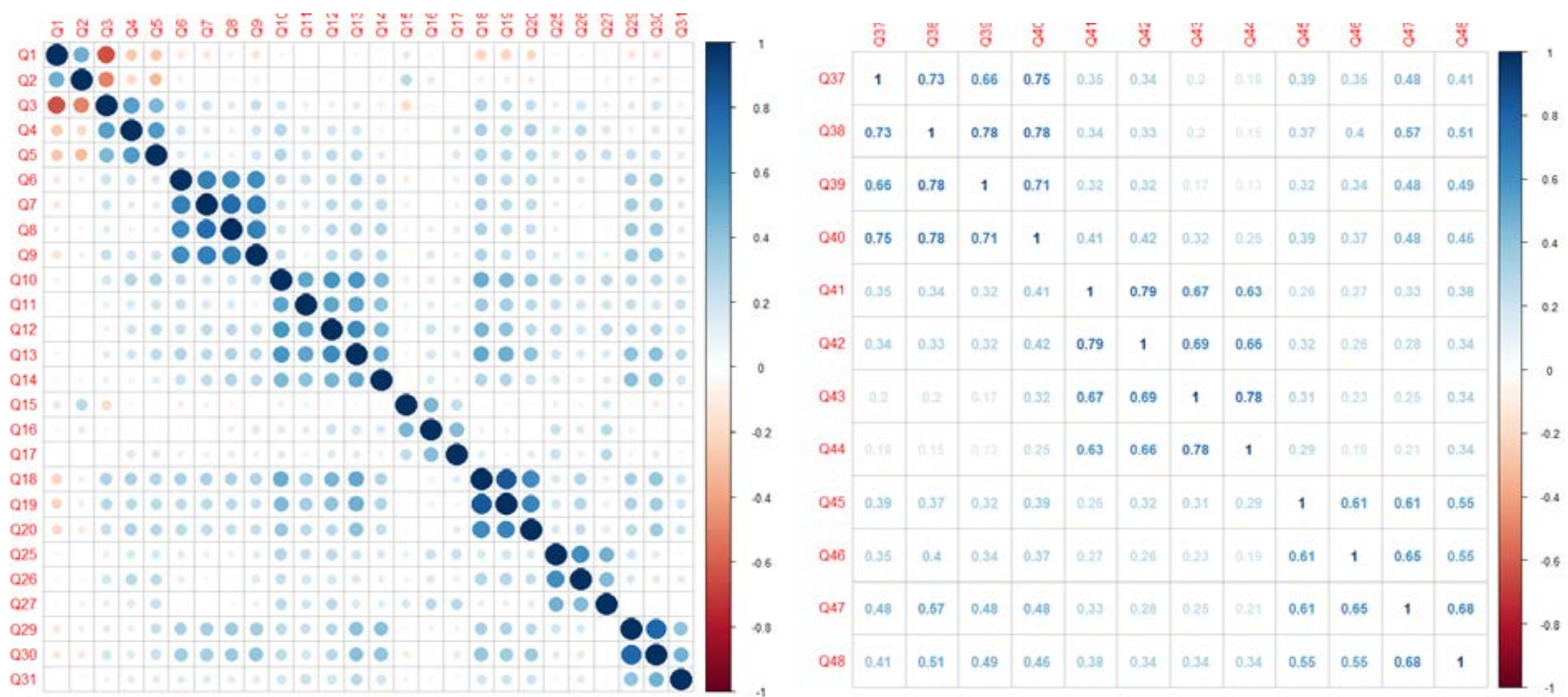

Figure 1. Items Correlation

Source: Author's calculation, 2020

Table 2

Exploratory factor analysis model

\begin{tabular}{|c|c|c|c|}
\hline & Items & Loadings & Cronbach Alpha \\
\hline \multirow{5}{*}{ 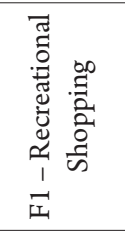 } & Shopping is not a pleasant activity. & 0.664 & \multirow{5}{*}{0.78} \\
\hline & Shopping in different stores is a waste of time. & 0.627 & \\
\hline & Shopping is very enjoyable for me. & 0.864 & \\
\hline & I enjoy shopping just for fun. & 0.504 & \\
\hline & It is fun to buy something new and exciting. & 0.523 & \\
\hline \multirow{4}{*}{ 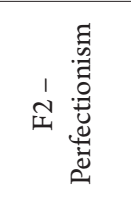 } & I make a special effort to choose the best quality products. & 0.728 & \multirow{4}{*}{0.89} \\
\hline & In general, I usually try to buy the best overall quality. & 0.896 & \\
\hline & Getting good quality is important to me. & 0.859 & \\
\hline & I have remarkably high standards and expectations for the products I buy. & 0.752 & \\
\hline \multirow{5}{*}{ 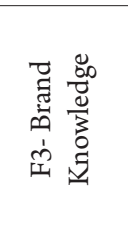 } & The most advertised brands are good choices. & 0.678 & \multirow{5}{*}{0.84} \\
\hline & The higher the price of the product, the better the quality. & 0.706 & \\
\hline & I prefer buying best-selling brands. & 0.751 & \\
\hline & I usually buy well-known brands. & 0.670 & \\
\hline & Good quality department stores and specialty stores offer the best. & 0.552 & \\
\hline \multirow{3}{*}{  } & I am confused by all the information on different products. & 0.548 & \multirow{3}{*}{0.64} \\
\hline & The more I learn about products, the harder it seems to choose the best. & 0.816 & \\
\hline & There are so many brands to choose from that I often feel confused. & 0.510 & \\
\hline \multirow{3}{*}{ 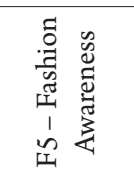 } & I usually have at least one outfit of the newest style. & 0.846 & \multirow{3}{*}{0.88} \\
\hline & I keep my wardrobe up to date with the changing fashions. & 0.914 & \\
\hline & Fashionable, attractive styling is important to me. & 0.634 & \\
\hline \multirow{3}{*}{ 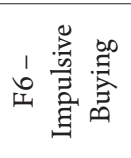 } & I often make purchases I later wish I had not. & 0.734 & \multirow{3}{*}{0.75} \\
\hline & I frequently purchase on impulse. & 0.807 & \\
\hline & I should spend more time deciding on the products I buy. & 0.498 & \\
\hline \multirow{3}{*}{ 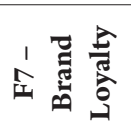 } & When I find a brand I like, I buy it regularly. & 0.792 & \multirow{3}{*}{0.79} \\
\hline & I have favorite brands I buy every time. & 0.960 & \\
\hline & I go to the same store each time I shop. & 0.463 & \\
\hline
\end{tabular}

Source: Author's calculation, 2020; Scale items were adapted from Sproles and Kendall, 1986 
Vol. 2 No. 1, 2021

Table 3

Results exploratory factor analysis on the perceived value dimension

\begin{tabular}{|c|c|c|c|}
\hline & Items & Loadings & Cronbach Alpha \\
\hline \multirow{4}{*}{ 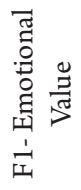 } & Slow fashion clothing has an acceptable standard of quality. & 0.783 & \multirow{4}{*}{0.92} \\
\hline & Slow fashion clothing is one that I would feel relaxed about using. & 0.887 & \\
\hline & Slow fashion clothing would make me want to use it. & 0.834 & \\
\hline & Slow fashion clothing is one that I would enjoy. & 0.836 & \\
\hline \multirow{4}{*}{ 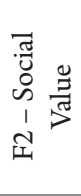 } & Slow fashion clothing would improve the way I am perceived. & 0.772 & \multirow{4}{*}{0.90} \\
\hline & Slow fashion clothing would make a good impression on other people. & 0.819 & \\
\hline & Slow fashion clothing would give its owner social approval. & 0.866 & \\
\hline & Slow fashion clothing would help me to feel acceptable. & 0.851 & \\
\hline \multirow{4}{*}{ 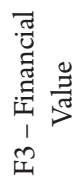 } & Slow fashion clothing is reasonably priced. & 0.751 & \multirow{4}{*}{0.86} \\
\hline & Slow fashion clothing would be economical. & 0.814 & \\
\hline & Slow fashion clothing is a good product for the price. & 0.800 & \\
\hline & Slow fashion clothing offers value for money. & 0.634 & \\
\hline
\end{tabular}

Source: Author's calculation, 2020. Scale items were adapted from Sweeney and Soutar, 2001

AGFI $\geq 0.90)$, Tucker-Lewis Index (TLI $\geq 0.95)$, Comparative Fit Index (CFI $\geq 0.90)$, root mean square error of approximation (RMSEA < 0.08) and standardized root mean square residual (SRMR < 0.08). The seven factors model concerning the decision-making process fit well on the data, registering good scores of the fit indices $(\mathrm{GFI}=0.981$, AGFI $=0.974$, TLI $=0.914$, CFI $=0.926$, RMSEA $=0.056$, SRMR $=0.062)$. The same good results were obtained in the case of the perceived value dimension, but the Tucker-Lewis Index registers a score slightly above the threshold; while the root mean square error of approximation registers a score above the threshold (GFI $=0.978$, AGFI $=0.960$, TLI $=0.926$, CFI $=0.943$, RMSEA $=0.096$, SRMR $=0.049)$.

\subsection{Hypotheses testing}

To test the proposed hypotheses, it was applied a structural equation model, implemented using the lavaan package (Rosseel, 2012). The gathered results were graphically outlined in the following image (Figure 2).



Notes: F1 = Recreational shopping; F2 = Perfectionism; F3 = Brand knowledge; F4 = Over choice confusion; F5 = Fashion awareness; F6 = Impulsive buying; F7 = Brand Loyalty; F8 = Emotional value; $\mathrm{F} 9=$ Social value; $\mathrm{F} 10=$ Financial value;

Figure 2. Results of the Structural Equation Model Estimation

Source: authors' calculation, 2020 
Table 4

Direct Effects - Hypotheses Testing

\begin{tabular}{|c|c|c|c|c|}
\hline Direct Effects & Estimate & Standard Error & z-value & P-value \\
\hline Emotional value $\sim$ Recreational shopping & -0.002 & 0.057 & -0.028 & 0.978 \\
\hline Emotional value $\sim$ Perfectionism & 0.102 & 0.057 & 1.788 & 0.074 \\
\hline Emotional value $\sim$ Brand knowledge & -0.011 & 0.086 & -0.131 & 0.896 \\
\hline Emotional value $\sim$ Over choice confusion & 0.291 & 0.090 & 3.249 & $0.001^{* *}$ \\
\hline Emotional value $\sim$ Fashion awareness & -0.010 & 0.049 & -0.202 & 0.840 \\
\hline Emotional value $\sim$ Impulsive buying & -0.064 & 0.051 & -1.257 & 0.209 \\
\hline Emotional value $\sim$ Brand loyalty & 0.052 & 0.046 & 1.136 & 0.256 \\
\hline Emotional value $\sim$ Gender & 0.301 & 0.133 & 2.259 & $0.024^{*}$ \\
\hline Social value $\sim$ Recreational shopping & 0.002 & 0.065 & 0.024 & 0.981 \\
\hline Social value $\sim$ Perfectionism & 0.064 & 0.065 & 0.024 & 0.981 \\
\hline Social value $\sim$ Brand knowledge & 0.102 & 0.099 & 1.037 & 0.300 \\
\hline Social value $\sim$ Over choice confusion & 0.179 & 0.098 & 1.832 & 0.067 \\
\hline Social value $\sim$ Fashion awareness & 0.123 & 0.056 & 2.183 & $0.029^{*}$ \\
\hline Social value $\sim$ Impulsive buying & 0.085 & 0.058 & 1.463 & 0.143 \\
\hline Social value $\sim$ Brand loyalty & 0.048 & 0.053 & 0.916 & 0.360 \\
\hline Social value $\sim$ Gender & -0.222 & 0.152 & -1456 & 0.145 \\
\hline Financial value $\sim$ Recreational shopping & 0.005 & 0.049 & 0.094 & 0.925 \\
\hline Financial value $\sim$ Perfectionism & 0.061 & 0.049 & 1.233 & 0.217 \\
\hline Financial value $\sim$ Brand knowledge & 0.034 & 0.075 & 0.454 & 0.649 \\
\hline Financial value $\sim$ Over choice confusion & 0.158 & 0.075 & 2.104 & $0.035^{*}$ \\
\hline Financial value $\sim$ Fashion awareness & 0.013 & 0.043 & 0.306 & 0.760 \\
\hline Financial value $\sim$ Impulsive buying & -0.037 & 0.044 & -0.829 & 0.407 \\
\hline Financial value $\sim$ Brand loyalty & 0.086 & 0.040 & 2.126 & $0.034^{*}$ \\
\hline Financial value $\sim$ Gender & -0.037 & 0.115 & -0.317 & 0.751 \\
\hline \multicolumn{5}{|c|}{ FIT INDICES } \\
\hline \multicolumn{5}{|c|}{$\mathbf{C F I}=0.915 ;$ TLI $=0.904 ; \mathbf{R M S E A}=0.052 ; \mathbf{S R M R}=0.061 ;$} \\
\hline
\end{tabular}

Source: authors' calculation, 2020

The results of the structural equation models (Table 4), that test potential relationships between decision-making dimensions and their perceived value toward slow fashion, identified several significant influences. In this respect, it was identified that over choice confusion exhibits a positive effect on the emotional value $(\beta=0.291$, $p$-value $=0.001)$ and on the financial value $(\beta=0.158$, $p$-value $=0.035)$; fashion awareness manifests a positive impact on the social value $(\beta=0.123$, $p$-value $=0.029)$, while brand loyalty manifests a positive influence on the financial value $(\beta=0.086$, $\mathrm{p}$-value $=0.034)$.

Regarding the gender influence on the perceived value, gender variable was transformed in a binary variable that takes the value of 0 if a respondent is a male and a value of 1 if a respondent is a female. In the case of the gender influence on the emotional value, we identified that if a respondent is a female, the influence on the emotional dimension is positively increasing, the influence being also statistically significant $(\beta=0.301$, $p$-value $=0.024)$. On the other hand, we observed that if a respondent is a female the overall influence on the social $(\beta=-0.222$, $p$-value $=0.145)$ and financial value $(\beta=-0.037, \mathrm{p}$-value $=0.751)$ is negative and not statistically significant.
Overall, the model that we have tested proved to registers good scores of the fit indices, namely the Comparative Fit Index (CFI $=0.915)$, root mean squared error of approximation (RMSEA = $0.052)$, and standardized root mean square residual $(\mathrm{SRMR}=0.061)$ registered desirable values. Regarding the Tucker Lewis Index, the obtained value is slightly below the 0.95 threshold.

\section{General discussion and implications}

The present research aimed to contribute to the slow fashion literature by supplying empirical evidence about the consumer's decision-making styles in understanding their perceived value toward slow fashion. The existing literature revealed that the decision-making style scale includes eight factors, namely, recreational shopping consciousness, perfectionism, brand consciousness, confusion by over choice, fashion consciousness, price consciousness, impulsiveness, and brand loyalty. The perceivedvalue scale is composed of four factors, namely the emotional, social, price, and quality values.

In the exploratory analysis that we conducted, we have found that in the case of the decision- 
making styles, the price consciousness loadings were exceptionally low, and the reliability score was poor performing. Therefore, we decided to drop it from the analysis. The same happened to the quality value from the perceived-value scale.

Regarding the hypotheses testing, we noticed that over choice confusion presents a positive impact on the emotional and financial values. While fashion consciousness manifests a positive impact on social value and brand loyalty shows a positive influence on financial value. The positive impact of fashion awareness on the price value was expected considering the results of existing research (Sung and Woo, 2019).

Regarding the gender influence on the emotional value, it was remarked that if a respondent is a female, the impact is positively improving by 0.301 , being also statistically significant.

We consider that those findings are in the interest of fashion retailers to develop proper marketing strategies for consumers to enhance their interest in slow fashion. Also, it is essential to make consumers aware of the positive features of the slow fashion, the time and financial benefits in the long term, the high quality offered while supplying the environmental protection function.

\section{Limitations and future research}

Even if the present research contributes to existing literature about the slow fashion movement and our empirical evidence could be in the interest of fashion retailers to develop appropriate strategies to contribute to a positive attitude toward slow fashion, some limitations should be kept in mind when generalizing the gathered results. The results have limited generalizability considering the sampling method that we have used to collect the data, namely the snowballing sample procedure. Moreover, our sample is unbalanced because we have more women $(79.00 \%)$ than men (21.00\%) respondents and more people from urban areas $(68.3 \%)$ than from rural areas $(31.7 \%)$. From the fact that most of the respondents reported a net monthly income lower than \$225 (44.9\%), we question that they are willing to invest lots of money in clothing acquisition. Considering those aspects, we believe that there is a need to extend the present research to a more homogeneous and unbalanced sample.

For the future, we propose to investigate the consumer's perceived value influence on their attitude and their purchase intention about the slow fashion phenomena.

\section{References:}

Claudy, M. (2011). An empirical investigation of consumer resistance to green product innovation, Doctoral thesis, Dublin Institute of Technology, Dublin.

Goldsmith, R. E., Flynn, L. R., \& Kim, D. (2010). Status Consumption and Price Sensitivity. Journal of Marketing Theory and Practice, 18(4), 323-338.

Puiu, I. A. (2019). Consumer Resistance to Innovation in the Fashion Industry. Studies in Business and Economics, 14(2), 127-140.

R Core Team, R. (2020). A language and environment for statistical computing. R Foundation for Statistical Computing, Vienna, Austria. Available at: https://www.R-project.org/

Rosseel, Y. (2012). Lavaan: An R Package for Structural Equation Modelling. Journal of Statistical Software, 48(2), 1-36. Available at: http://www.jstatsoft.org/v48/i02/

Sproles, G. B. (1985). From perfectionism to faddism: measuring consumers' decision-making styles. In: Proceedings, American Council on Consumer Interests, 31, 79-85.

Sproles, G. B., \& Kendall, E. L. (1986). A methodology for profiling consumers' decision-making styles. The Journal of Consumer Affairs, 20(2), 267-279.

Stankevich, A. (2017). Explaining the Consumer Decision-Making Process: Critical Literature Review. Journal of International Business Research and Marketing, 2(6), 7-14.

Sung, J., \& Woo, H. (2019). Investigating male consumers' lifestyle of health and sustainability (LOHAS) and perception toward slow fashion. Journal of Retailing and Consumer Services, 49, 120-128.

Sweeney, J. C., \& Soutar, G. N. (2001). Consumer perceived value: The development of a multiple item scale, Journal of Retailing, 77, 203-220.

Tversky, A., \& Kahneman, D. (1991). Loss Aversion in Riskless Choice: A Reference-Dependent Model. The Quarterly Journal of Economics, Oxford University Press, 106(4), 1039-1061. 